\title{
Profile of Children Treated for Uncomplicated Intussusception in a Tertiary Hospital in Enugu, Nigeria
}

Chukwubuike Kevin Emeka

Pediatric Surgery Unit, Department of Surgery, Enugu State University Teaching Hospital, Enugu, Nigeria.

*Corresponding Author: Chukwubuike Kevin Emeka, Department of Surgery, Enugu State University Teaching Hospital, Enugu, Nigeria.

Received date: February 10, 2020: Accepted date: February 27, 2020: Published date: March 02, 2020

Citation: Chukwubuike K Emeka. (2021) Profile of Children Treated for Uncomplicated Intussusception in a Tertiary Hospital in Enugu, Nigeria. Journal of Clinical Surgery and Research. 2(1) DOI: 10.31579/2768-2757/005

Copyright: (92021 Chukwubuike Kevin Emeka, This is an open-access article distributed under the terms of the Creative Commons Attribution License, which permits unrestricted use, distribution, and reproduction in any medium, provided the original author and source are credited.

\section{Abstract}

Background: Intussusception is a common cause of intestinal obstruction in infants. The aim of study was to evaluate our experience in the management of children who presented with uncomplicated intussusception.

Materials and Methods: This was a retrospective study of children (12 months and younger) who were treated for uncomplicated intussusception (ultrasound confirmed) between January 2014 and December 2018, at the pediatric surgery unit of Enugu State University Teaching Hospital (ESUTH) Enugu, Nigeria.

Results: There were 255 cases of intussusception seen during the 5-year study period. Out of this number, 85 (33.3\%) patients had uncomplicated intussusception. There was male predominance and the ages of the patients ranged from 4 to 12 months with a mean age of 6 months. Abdominal pain was the most common symptom in the patients. On the average, one-fifth of the patients had a preceding history of respiratory and enteral infection. Half of the patients had a hemoglobin level of less than $10 \mathrm{~g} / \mathrm{dl}$ at presentation. Abdominal ultrasound was the imaging modality of choice and was diagnostic in all the patients. Three-quarters of the patients were successfully treated by hydrostatic reduction and there was recurrence of intussusception in 2 patients. There was no mortality.

Conclusion: Only one-third of our patients present with uncomplicated intussusception during the study period. Non-operative (hydrostatic reduction) treatment is an effective modality of treatment for uncomplicated intussusception.

Keywords: children; intussusception; tertiary hospital; uncomplicated

\section{Introduction}

Intussusception is the invagination of a segment of the bowel into another segment. The part of the bowel that invaginates is the intussusceptum while the part that receives the invaginating segment is the intussuscipiens [1]. Intussusception is a pediatric abdominal surgical emergency and one of the most common causes of intestinal obstruction in infants [2]. The clinical presentation of intussusception may vary from one patient to another. However, classically, the symptoms of intussusception include abdominal pain, vomiting and passage of red currant jelly stool [3]. However, these classical symptoms are found only in about 20 percent of the patients [4]. Abdominal ultrasound is diagnostic imaging of choice for the diagnosis of intussusception due to its high sensitivity and specificity [5]. Treatment of intussusception in children could be non-operative or operative. Non-operative treatment is in the form hydrostatic (using normal saline, Hartmann's solution or barium) or pneumatic reduction (using air) [6]. Operative treatment of intussusception is indicated in the following conditions: failed hydrostatic reduction, features of peritonitis or marked abdominal distension [6]. Children with intussusception who present early are treated non-operatively with little or no complications. However, only a few patients present early most likely due to poverty and low levels of enlightenment. The aim of study was to evaluate our experience in the management of children who presented with uncomplicated intussusception. For the purposes of this study, uncomplicated intussusception refers to intussusception without intestinal gangrene, without perforation and without features of peritonitis.

\section{Materials and Methods}

This was a retrospective study of children (less than 12 months of age) who were treated for uncomplicated intussusception (ultrasound confirmed) between January 2014 and December 2018, at the pediatric surgery unit of Enugu State University Teaching Hospital (ESUTH) Enugu, Nigeria. Consecutive children who presented with ultrasound confirmed intussusception during the study period were enrolled into the study. Children with uncomplicated intussusception treated nonoperatively and operatively were evaluated. Patients with incomplete medical records and those with complicated intussusception were excluded from the study. ESUTH is a tertiary hospital located in Enugu, South East Nigeria. The hospital serves the whole of Enugu State, which according to the 2016 estimates of the National Population Commission and Nigerian National Bureau of Statistics, has a population of about 4 million people and a population density of $616.0 / \mathrm{km}^{2}$. The hospital also 
receives referrals from its neighboring states. Ethical approval was obtained from Ethics and Research committee of the hospital.

\section{Pre-operative protocol}

On presentation, the patients were clinically evaluated and appropriate investigations (hematological, biochemical and imaging) performed. The procedure was explained to the parents/caregiver and informed consent for treatment obtained. All the patients were resuscitated using intravenous fluids and antibiotics (ceftriaxone and metronidazole).

\section{Procedure proper}

Hydrostatic reduction of intussusception (non-operative) was attempted in all the patients. Operative treatment was performed when there was failure of hydrostatic reduction or features of peritonitis.

\section{Post-operative protocol}

Analgesics and antibiotics were given to patients that had laparotomy. Oral intake was commenced when bowel function returned.

\section{Data collection}

Information was extracted from the case notes, operation notes, operation register, and admission-discharge records. The information extracted included the age, gender, duration of symptoms before presentation, time interval between presentation and intervention, presenting symptoms, modality of treatment, complications of treatment, duration of hospital stay and outcome of treatment.

\section{Data analysis}

Statistical Package for Social Science (SPSS) version 23, manufactured by IBM Cooperation Chicago Illinois, USA, was used for data entry and analysis. Data were expressed as percentages, means and medians.

\section{Results}

\section{Patients' demographics}

There were 255 cases of intussusception seen during the 5-year study period. Out of this number, $85(33.3 \%)$ patients had uncomplicated intussusception and formed the basis of this report. Demographic features of the 85 patients are shown in Table 1.

\begin{tabular}{|c|c|}
\hline Gender & Number of patients (\%) \\
\hline Male & $62(72.9 \%)$ \\
\hline Female & $23(27.1 \%)$ \\
\hline Mean age & 6 months (range: 4-12) \\
\hline Peak age & 5 months \\
\hline Duration of symptoms before presentation & 4 days (1-7) \\
\hline Median duration from presentation to treatment & 1 days (1-3) \\
\hline Mean duration of hospital stay & 4 days (2-6) \\
\hline
\end{tabular}

Table 1: Demographic features of patients $(n=85)$

\section{Presenting clinical features of the patients}

Abdominal pain was the most common symptom the patients presented with. Other symptoms are depicted in Table 2.

\begin{tabular}{|c|c|}
\hline Presenting symptom & Number of patients (\%) \\
\hline Abdominal pain + vomiting + red currant jelly stool & $45(52.9)$ \\
\hline Abdominal pain + fever + vomiting & $33(38.8)$ \\
\hline Abdominal pain + red currant jelly stool & $21(24.7)$ \\
\hline Vomiting + palpable abdominal mass & $16(18.2)$ \\
\hline Non-specific symptoms & $5(5.9)$ \\
\hline
\end{tabular}

Table 2: Presenting clinical features

\section{Any preceding viral infection}

Twenty-two $(25.9 \%)$ patients had a history of respiratory tract infection while $15(17.6 \%)$ patients had enteritis preceding onset of symptoms of intussusception. Six $(7.1 \%)$ patients had evidence of both respiratory and intestinal infections.

\section{Investigations done}

\section{Hematological and biochemical}

At presentation, $41(48.2 \%)$ patients had a hemoglobin level of less than 10 grams per deciliter $(\mathrm{g} / \mathrm{dl})$. There was serum electrolyte derangement in $28(32.9 \%)$ patients.

\section{Imaging}

Seventeen $(20 \%)$ patients had a plain abdominal $\mathrm{x}$ ray which showed features of intestinal obstruction. None of the $\mathrm{x}$ rays was diagnostic of intussusception. All the patients had an abdominal ultrasound that confirmed intussusception. No patient had computed tomography (CT) scan, or magnetic resonance imaging (MRI).

Treatment offered and operative finding
Hydrostatic reduction of intussusception was attempted in all the 85 patients. However, hydrostatic reduction was successful in $64(75.3 \%)$ patients. Failure of hydrostatic reduction in $21(24.7 \%)$ patients was the indication for operative treatment of intussusception. At surgery, the bowel was manually reduced and found to be viable.

\section{Post-treatment complications}

Among the patients treated by hydrostatic reduction, two patients developed recurrent intussusceptions which were treated successfully by a repeat hydrostatic reduction. Among the patients treated operatively, there was surgical site infection in $3(3.5 \%)$ patients and incisional hernia in $2(2.4 \%)$ patients.

\section{Management outcome}

All the patients achieved full recovery and were discharged home. There was no mortality.

\section{Discussion}

Intussusception in children is mostly known to be idiopathic without any underlying cause. However, pathological lead point can also lead to intussusception in children. Early presentation and prompt treatment of 
intussusception prevents complications while late presentation is associated with complications such as bowel ischemia and gangrene [7, 8]. Complications occurring in intussusception entail more invasive procedures, higher cost of treatment and long hospital stay.

In the present study, majority of the patients presented with complicated intussusception; only one-third of the patients presented with uncomplicated intussusception. Poverty and ignorance that is prevalent in low income countries may explain this low number of uncomplicated intussusceptions. The male predominance recorded in the present study is consistent with the report of other authors [1,9]. However, one study from Kano, Nigeria reported that more females than males were affected by intussusception [10]. The reason for the gender differences is not known. The age range of our patients is comparable to the report of other researchers $[11,12]$. It is worthy to note that intussusception can occur at any age. The late presentation of our patients is manifest in the mean 4day period before presentation to the hospital. Ekenze et al reported the late presentation of patients with intussusception and its implications [13]. This late presentation may be due to low level of awareness and enlightenment seen in developing countries. The one-day interval between presentation and treatment was the interval required for resuscitation and optimization of the patients. The mean duration of hospital stay of 4 days recorded in the index study reflects the less invasive procedures performed due to the uncomplicated nature of the intussusception. Patients who underwent bowel resection for intussusception stay longer in the hospital [3].

Abdominal pain was the most common symptom in the current series. Other series on intussusception also reported abdominal pain as a common feature of intussusception [12, 14]. Painless intussusception can occur in infants that are less than 4 months of age [12]. In patients presenting late, abdominal distension may be the most common symptom of intussusception [3]. The classical triad of abdominal pain, passage of red currant jelly stool and vomiting was found in about 50 percent of the patients. Chalya et al in their series on intussusception also reported that half of their patients presented with this classical symptoms. One study from Netherlands documented the classic symptoms in about one-third of the patients [15]. Non-specific symptoms such as leathargy, diarrhea, fever, lethargy and listlessness have also been reported in intussusception [16].

Studies have demonstrated the presence of adenovirus in $30 \%$ to $50 \%$ of stool samples and in lymphoid tissue specimens from children with intussusception [17]. These findings suggest that viral infections play an important role in the development of intussusception [18]. About onequarter of the patients had respiratory tract infection and one-fifth of the patients had intestinal infection which preceded the onset of symptom of intussusception. These viral infections were characterized by cough, nasal discharge, and diarrhea. Other studies also found an association between viral infections and intussusception $[19,20]$.

At presentation, about $50 \%$ of the patients had a hemoglobin level of less than $10 \mathrm{~g} / \mathrm{dl}$ and there was electrolyte derangement in one-third of the patients. The low hemoglobin level may be pre-existing in these children due to malnutrition or parasitic infections that is common in developing countries. The passage of red currant (mucus mixed with blood) stool may also be responsible for the anemia and electrolyte imbalance since the mucus is high in electrolytes. One study from Enugu, Nigeria also reported the association between intussusception, anemia and electrolyte derangements [21].

Intussusception was confirmed in 100 percent of our patients through an abdominal ultrasound. Ultrasound has a sensitivity and specificity of near $100 \%$ for the diagnosis of intussusception [22]. Plain abdominal $\mathrm{x}$ ray could not make a definitive diagnosis of intussusception in any of the patients. This finding is comparable to the report of Chalya et al [3].
Similarly, Robson and Beasley reported that plain abdominal $\mathrm{x}$ ray is indicated when a clinical suspicion of intussusception is low [23]. However, Guo et al documented that about $45 \%$ of intussusception can be diagnosed through plain abdominal $x$ ray [24]. The level of expertise and experience of the radiologist may be responsible for the ability to detect intussusception in a plain abdominal $\mathrm{x}$ ray. CT scan and MRI were not done in any of the patients due to the risk of radiation exposure and cost respectively.

Uncomplicated intussusception is usually treated by non-operative means (through hydrostatic or pneumatic reduction). Operative treatment of uncomplicated intussusception is only indicated in cases of unsuccessful hydrostatic reduction. These were the treatments received by our patients. One study from Zaria, Nigeria reported laparotomy for uncomplicated intussusception which was what was obtainable in developing country like Nigeria as at the time of the study: The absence of the required expertise for non-operative treatment could explain the laparotomy for uncomplicated intussusception [25].

Following hydrostatic reduction, two of our patients developed recurrent intussusceptions. These recurrent intussusceptions were found to be ileocolic by ultrasound and were treated by repeat hydrostatic reduction. Other options of treatment of recurrent intussusception include operative intervention, ileocolopexy or resection of the involved portion of the intestine in cases of multiple recurrences [26, 27]. Among the patients treated operatively, surgical site infection was the most common postoperative complication. Ameh in his series on uncomplicated intussusception also recorded surgical site infection as the most common post-operative complication [25].

None of our patients expired. Howbeit, studies from northern and western Nigeria on intussusception reported a mortality of $8 \%$ and $12.1 \%$ respectively $[9,25]$. Mortality following treatment of intussusception may depend on clinical state of the patient and complications arising from the treatment.

\section{Conclusion}

In low income country like Nigeria, uncomplicated intussusception account for a small fraction of the total intussusception treated due to late presentation of the patients. More male were affected in the present study and the peak age was 5 months. Majority of the patients had abdominal pain. Abdominal ultrasound is the diagnostic method of choice and hydrostatic reduction was successful in most of the patient. No mortality was recorded.

\section{References}

1. Marsicovetere P, Ivatury SJ, White B, Holubar SD. (2017) Intestinal Intussusception: Etiology, Diagnosis, and Treatment. Clinical Colon Rectal Surgery.30:30-39.

2. Chukwubuike KE, Nduagubam OC, Ndu IK, Odetunde OA, Ekenze SO, Eze TC. Paediatric Abdominal Surgical Emergencies in Enugu, South East Nigeria: Any Change in Pattern and Outcome. European Journal of Clinical and Biomedical Sciences. 5(2): 39-42.

3. Chalya PL, Kayange NM, Chandika AB. (2014) Childhood intussusceptions at a tertiary care hospital in northwestern Tanzania: a diagnostic and therapeutic challenge in resourcelimited setting. Ital J Pediatr. 40(1): 28.

4. Tianyi FL, Kadia BM, Dimala CA. (2017) Delayed diagnosis of transanal prolapse of an ileo-colic intussusception in a 10month-old infant in rural Cameroon: a case report. BMC Res Notes. 10: 521.

5. Bartocci M, Fabrici G, Valente I, Manzoni C, Speca S, Bonomo L et al. (2018) Intussusception in childhood: role of sonography on diagnosis and treatment. J Ultrasound. 18(3): 205-211. 
6. Chukwubuike KE, Nduagubam OC. (2020) Hydrostatic reduction of intussusception in children: a single centre experience. Pan Afr Med J. 36(263): 1-7.

7. Huang HY, Huang XZ, Han JY, Zhu BL, Huang YK, Lin J, et al. (2017) Risk factors associated with intestinal necrosis in children with failed non-surgical reduction for intussusception. Pediatr Surg Int. 33(5): 575-580.

8. Egbuchulem KI, Lawal TA, Nweke MC, Adeoye AO. (2017) A case of compound intussusception in a Nigerian child - a rare finding in a common disease. Ann Ib Postgrad Med. 15(1): 5760.

9. Bode CO. (2008) Presentation and management outcome of childhood intussusception in Lagos. A prospective study. African Journal of Paediatric Surgery. 5: 24-28.

10. Edino ST, Ochicha O, Mohammed AZ, Anumah M. (2003) Intussusception in Kano: a 5-year analysis of pattern, morbidity and mortality. Niger J Med. 12: 221-224.

11. Jo S, Lim I. Chae S, Yun S, Lee N, Kim S, Yi D. (2019) Characteristics of intussusception among children in Korea: a national epidemiological study. BMC Pediatr,; 19, 211.

12. Kumar B, Kumar M, Sinha AK. (2019) Intussusceptions in children. Indian J Surg. 81: 379-382.

13. Ekenze SO, Mgbor SO. (2011) Childhood intussusception: the implications of delayed presentation. Afr J Paeditr Surg. 8(1): 15-18.

14. Yilma Y, Akmel M, Workicho A. (2018) A three-year study on childhood intussusception in Jimma University Medical Center. Medical Practice and Reviews. 9(1): 1-7.

15. Kleizen KJ, Hunck A, Wijnen MH, Draaisma JM. (2009) Neurological symptoms in children with intussusception. Acta Paediatr. 98(11): 1822-1824.

16. Paul SP, Candy DC, Pandya N. (2010) A case series on intussusception in infants presenting with listlessness. Infant. 6(5): 174-177.

17. Okimoto S, Hyodo S, Yamamoto M, Nakamura K, Kobayashi M. (2011) Association of viral isolates from stool samples with intussusception in children. International Journal of Infectious Diseases. 15(9): 641-645.
18. Lee YW, Yang SI, Kim JM, Kim JY. (2013) Clinical Features and Role of Viral Isolates from Stool Samples of Intussusception in Children. Peditr Gastroenterol Hepatol Nutr. 16(3): 162-170.

19. Mansour AM, Elkoutby M, El Barbary MM, Mohamed W, Shehata S, Mohammady HE. (2013) Enteric viral infections as potential risk factors for intussusception. J Infect Dev Ctries. 7(1): 28-35.

20. Burnett E, Kabir F, Trang NV, Rayamajhi A, Satter SM, Liu J et al. (2020) Infectious etiologies of intussusception among children <2 years old in 4 Asian countries. The Journal of Infectious Diseases. 221(9): 1499-1505.

21. Chukwubuike K. (2020) Intussusception in Children treated on the basis of clinical features: A prospective observational study from Enugu State, Nigeria. Medical Journal of Zambia. 47(3): 223-230.

22. Verschelden P, Filiatrault D, Garel L, Grignon A, Perreault G, Boisvert $\mathrm{J}$ et al. (1992) Intussusception in children: reliability of US in diagnosis-a prospective study. Radiology. 184(3): 741744.

23. Robson N, Beasley S. (2014) Role of plain abdominal radiography in the initial investigation of suspected intussusception. J Paediatr Child Health. 50(4): 251-252.

24. Guo WL, Wang J, Zhou M, Sheng M, Fang L. (2011) The role of plain radiography in assessing intussusception with vascular compromise in children. Arch Med Sci. 7(5): 877-881.

25. Ameh EA. (2002) The morbidity and mortality of laparotomy for uncomplicated intussusception in children. West Afr J Med. 21(2): 115-116.

26. Niramis R, Watanatittan S, Kruatrachue A, Anuntkosol M, Buranakitjaroen V, Rattanasuwan T et al. (2010) Management of recurrent intussusception: nonoperative or operative reduction? J Pediatr Surg. 45(11):2175-2180.

27. Burrington JD. (1980) Surgical technique for the prevention of recurrent intussusception in childhood. Surg Gynecol Obstet. 150(4): 572-573. 